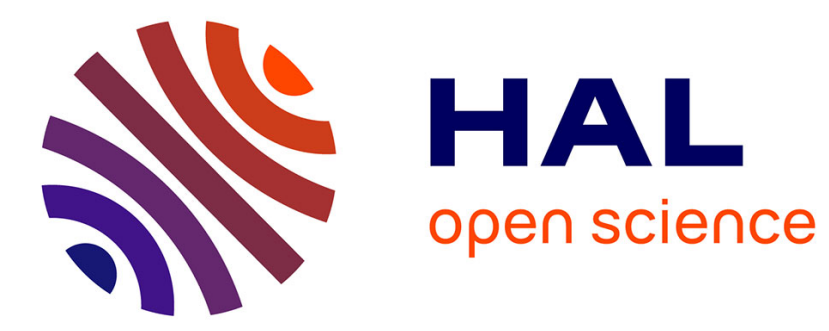

\title{
Electrical Characterization of Vertically Stacked p-FET SOI Nanowires
}

Bruna Cardoso Paz, Mikael Casse, Sylvain Barraud, Gilles Reimbold, Maud Vinet, Olivier Faynot, Marcelo Antonio Pavanello

\section{- To cite this version:}

Bruna Cardoso Paz, Mikael Casse, Sylvain Barraud, Gilles Reimbold, Maud Vinet, et al.. Electrical Characterization of Vertically Stacked p-FET SOI Nanowires. Solid-State Electronics, 2018, 141, pp.84-91. 10.1016/j.sse.2017.12.011 . cea-01974222

HAL Id: cea-01974222 https://hal-cea.archives-ouvertes.fr/cea-01974222

Submitted on 8 Jan 2019

HAL is a multi-disciplinary open access archive for the deposit and dissemination of scientific research documents, whether they are published or not. The documents may come from teaching and research institutions in France or abroad, or from public or private research centers.
L'archive ouverte pluridisciplinaire HAL, est destinée au dépôt et à la diffusion de documents scientifiques de niveau recherche, publiés ou non, émanant des établissements d'enseignement et de recherche français ou étrangers, des laboratoires publics ou privés. 


\title{
Electrical Characterization of Vertically Stacked p-FET SOI Nanowires
}

\author{
Bruna Cardoso Paz ${ }^{1}$, Mikaël Cassé ${ }^{2}$ Sylvain Barraud ${ }^{2}$, Gilles Reimbold ${ }^{2}$, Maud Vinet ${ }^{2}$, Olivier Faynot ${ }^{2}$ \\ and Marcelo Antonio Pavanello ${ }^{1}$
}

${ }^{1}$ Department of Electrical Engineering, Centro Universitário FEI, São Bernardo do Campo, Brazil
${ }^{2}$ Département des Composants Silicium - SCME/LCTE, CEA-LETI Minatec, Grenoble, France

bcpaz@fei.edu.br

Abstract - This work presents the performance and transport characteristics of vertically stacked p-type MOSFET SOI nanowires (NWs) with inner spacers and epitaxial growth of SiGe raised source/drain. The conventional procedure to extract the effective oxide thickness (EOT) and Shift and Ratio Method (S\&R) have been adapted and validated through tridimensional numerical simulations. Electrical characterization is performed for NWs with [110]- and [100]-oriented channels, as a function of both fin width (W $\mathrm{W}_{\text {FIN }}$ ) and channel length (L). Results show a good electrostatic control and reduced short channel effects (SCE) down to $15 \mathrm{~nm}$ gate length, for both orientations. Effective mobility is found around two times higher for [110]- in comparison to [100]-oriented NWs due to higher holes mobility contribution in (110) plan. Improvements obtained on $\mathrm{I}_{\mathrm{ON}} / \mathrm{I}_{\mathrm{OFF}}$ by reducing $\mathrm{W}_{\mathrm{FIN}}$ are mainly due to subthreshold slope decrease, once small and none mobility increase is obtained for [110]- and [100]-oriented NWs, respectively.

Keywords-performance; transport; electrical characterization; vertically stacked nanowire; SOI MOSFET; channel orientation

\section{INTRODUCTION}

Once increasing the number of gates results in stronger immunity against short channel effects due to higher electrostatic coupling, triple gate (3G) and Gate-All-Around (GAA) MOSFETs attracted the interest of both scientific community and semiconductor industry [1]-[3]. Multiple gate MOSFETs with nanoscale silicon thickness and fin width, also called nanowires, have shown great performance and scalability, turning into one of the best candidates for future technological nodes [2], [4]. In these devices the silicon film thickness and the fin width are of the same order of magnitude. 
The use of carrier mobility boosters, such as the implementation of different materials, mechanical stress and rotated substrates, demonstrated to be an important ally to the continuity of the CMOS roadmap, so multiple gate MOSFETs would be able to fulfill higher drive current requests imposed by the International Technology Roadmap for Semiconductors (ITRS). While the use of compressive and tensile stress can enhance holes and electrons mobility, respectively [5], [100]-orientated channel can boost n-type NWs current due to higher electrons mobility along (100) sidewalls [6].

Thanks to advances on tridimensional integration process, vertically stacked nanowires have been fabricated to increase the on-state current by footprint $\left(\mathrm{I}_{\mathrm{ON}} / \mathrm{W}_{\mathrm{FIN}}\right)$ due to higher device aspect ratio, once the overall channel width $\left(\mathrm{W}_{\text {eff }}\right)$ is proportional to the number of beams [7]-[9]. On the other hand, stacking nanowires makes the reduction of intrinsic parasitic capacitances one of the main challenges to the implementation of such transistors.

Recently, vertically stacked p-type NW MOSFETs have been fabricated combining inner spacers and $\mathrm{SiGe}$ source/drain for the first time. This innovative structure aims to contribute for alleviating two problems at the same time, reducing the intrinsic parasitic capacitances and boosting carriers' mobility [9]. In this work, a systematic electrical characterization of these advanced transistors is presented, deepen and expanding the preliminary results of [10] and their interpretation.

Precise EOT extraction is crucial to allow further investigations of any new technology, because EOT consists on an important parameter that defines the structure and it is required in different methodologies of electrical characterization, such as Y-function method [10]. Although wide-planar transistors ( $\mathrm{W}_{\mathrm{FIN}}$ on the order of micrometers) are adequate test structures to extract EOT due to big channel area, such devices are not available as stacked nanowires because limitations during the selective etching step reveals remaining SiGe along the channel of wide stacked MOSFETs. Moreover, using standard fitting procedures of expressions that depend on the $\mathrm{W}_{\text {eff }}$ may lead to significant errors in EOT because of imprecisions on determining the real $\mathrm{W}_{\text {eff }}$ of experimental narrow NWs. To overcome these problems, a different approach to extract EOT is presented, based on capacitance measurements, and the results are confirmed by tridimensional numerical simulations.

The Shift and Ratio Method (S\&R) was developed and modified in literature to extract the effective physical values for either the channel length or the fin width [11], [12] after the device fabrication. Although the method has been already applied to multiple gate transistors, its implementation considered constant mobility and used planar transistors ( $\mathrm{W}_{\mathrm{FIN}}$ up to $10 \mu \mathrm{m}$ ) as reference devices. 
Applying S\&R to extract the fin width of aggressive scaled nanowires without using wide-planar transistors as reference requires a modified systematic procedure, which is also proposed in this work.

Performance and transport characteristics are discussed through $\mathrm{I}_{\mathrm{ON}} / \mathrm{I}_{\mathrm{OFF}}$ behavior, threshold voltage $\left(\mathrm{V}_{\mathrm{TH}}\right)$, subthreshold slope $(\mathrm{SS})$, DIBL, series resistance $\left(\mathrm{R}_{\mathrm{S}}\right)$ and effective mobility $\left(\mu_{\mathrm{eff}}\right)$. The discussion on the performance of the fabricated stacked NWs is taken as a function of both fin width and channel length, for NWs orientated along [110] and [100] directions.

The paper is organized as follows: Section II details the devices characteristics. Section III presents the proposed modifications on EOT (Section III-A) and Shift and Ratio (Section III-B) methods, followed by the extracted mentioned electrical (section III-C) and transport (Section III-D) characteristics. Finally, the conclusions of this work are pointed out in Section IV.

\section{DEVICES DESCRIPTION}

Vertically stacked p-type nanowires MOSFETs with two levels (also called beams) have been fabricated at CEA-LETI, starting from Silicon-On-Insulator (SOI) wafers with $145 \mathrm{~nm}$ buried oxide thickness and using a replacement metal gate (RMG) process. Transmission Electron Microscopy (TEM) images of the studied stacked NWs cross section (a) and the longitudinal section (b) are presented in Figure 1. The bottom level $\mathrm{NW}$ is $\Omega$-gate (triple gate) type architecture and the top level is GAA one. Each level has a $10 \mathrm{~nm}$ thick Si channel $\left(\mathrm{t}_{\mathrm{Si}}\right)$ and both levels are attached by common metal gate and $\mathrm{Si}_{0.7} \mathrm{Ge}_{0.3}: \mathrm{B}$ raised source/drain. The transistors have been fabricated in multi finger structures with 50 fins in parallel, along two different crystallographic orientations, [110] and [100], and present a gate stack composed by $\mathrm{HfO}_{2} / \mathrm{TiN} / \mathrm{W}$. Further fabrication details of the stacked-NWs studied in this work can be found in [9].

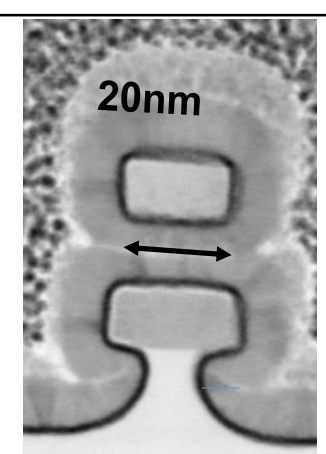

(a)

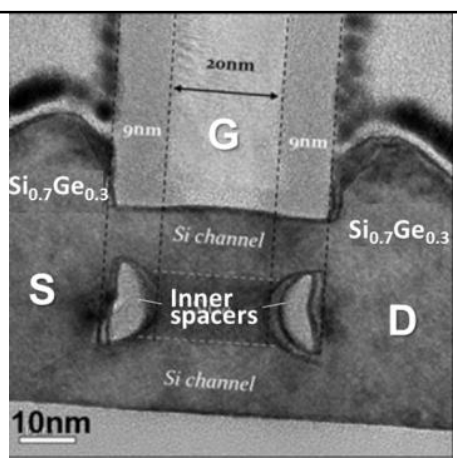

(b)

Figure 1. Vertically stacked SOI nanowire cross section (a) and longitudinal section (b) TEM images. 


\section{RESULTS AND DISCUSSION}

\section{A. EOT extraction}

In order to extract the EOT obtained from the gate stack deposition process, $\mathrm{C}-\mathrm{V}$ measurements were performed in stacked NWs with different $\mathrm{W}_{\mathrm{FIN}}$ and same long L. To overcome the limitation on EOT extraction imposed by the absence of wide stacked NWs, we developed an alternative procedure as follows. By taking the difference between the capacitance of two adjacent transistors with different fin width, $\mathrm{C}_{\mathrm{GC}, 1}$ and $\mathrm{C}_{\mathrm{GC}, 2}$, as indicated in Figure 2, the following expression to the differential gate to channel capacitance per unit of area $\left(\mathrm{C}_{\mathrm{GC}}{ }^{\prime}\right)$ can be obtained:

$$
\mathrm{C}_{\mathrm{GC}}{ }^{\prime}=\frac{\mathrm{C}_{\mathrm{GC}, 2}-\mathrm{C}_{\mathrm{GC}, 1}}{3 \times \Delta \mathrm{W} \times \mathrm{L}}
$$

It is important to note that $\mathrm{C}_{\mathrm{GC}}$ ' does not dependent on $\mathrm{W}_{\text {eff }}$ (calculated by $4 \mathrm{t}_{\mathrm{Si}}+3 \mathrm{~W}_{\mathrm{FIN}}$ ), but on $\Delta \mathrm{W}$, which is equal to the difference between the fin width masks, $\mathrm{W}_{\mathrm{FIN}, \text { mask,2 }}-\mathrm{W}_{\mathrm{FIN}, \text { mask, }, \text {, and consists in }}$ a more reliable parameter, since systematic mismatches between the top and bottom levels and between the mask and real fin widths are suppressed.

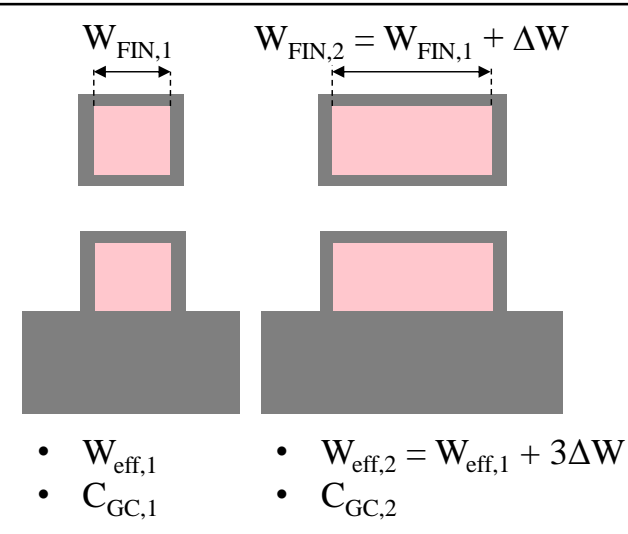

Figure 2. Schematics of two stacked NWs with different fin widths. If the difference between their fin width mask is $\Delta \mathrm{W}$, the effective channel width of the wider stacked NW corresponds to the effective channel width of the narrower stacked NW plus $3 \times \Delta \mathrm{W}$.

The experimental results of $\mathrm{C}_{\mathrm{GC}}$ ' have been fitted to modelled curves obtained from a $2 \mathrm{D}$ Poisson-Schrödinger solver considering quantum confinement effects for fully depleted SOI layers [13], [14]. Fitting procedure has been carried out by comparing measured $\mathrm{C}_{\mathrm{GC}}$ 'values at high gate voltage overdrive $\left(\mathrm{V}_{\mathrm{GT}}=\mathrm{V}_{\mathrm{GS}}-\mathrm{V}_{\mathrm{TH}}\right)$ to modelled curves to obtain EOT that leads to the best adjustment. Figure 3 presents $\mathrm{C}_{\mathrm{GC}}$ ' as a function of the gate voltage overdrive for stacked NWs with $\mathrm{L}=100 \mathrm{~nm}$ and $\Delta \mathrm{W}=50$ $\mathrm{nm}$, where the extracted EOT is equal to $1.15 \pm 0.1 \mathrm{~nm}$. It is important to mention that the presented methodology can be applied as described in cases where $\mathrm{V}_{\mathrm{TH}}$ mismatches are observed between the two transistors, because $\mathrm{C}_{\mathrm{GC}, 1}$ and $\mathrm{C}_{\mathrm{GC}, 2}$ are taken at the same $\mathrm{V}_{\mathrm{GT}}$ to minimize the effect of $\mathrm{V}_{\mathrm{TH}}$ differences. 


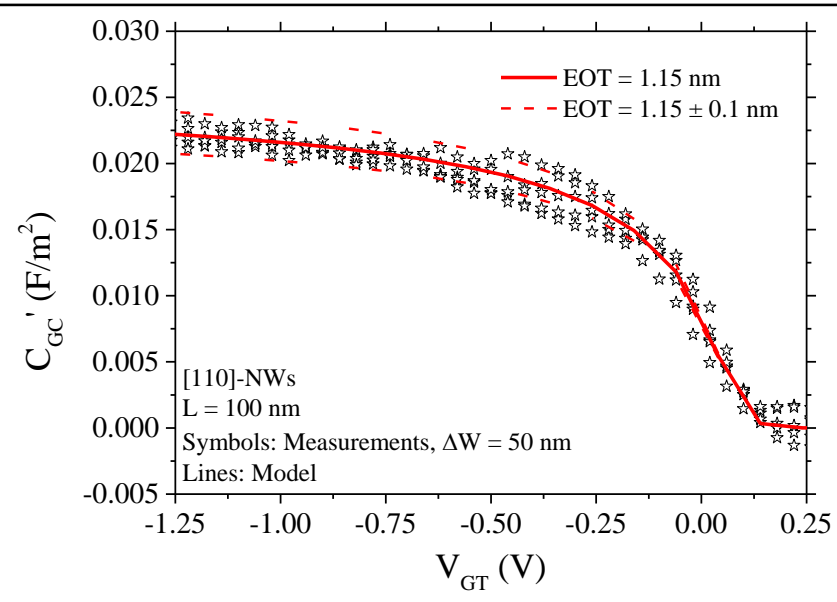

Figure 3. Differential gate to channel capacitance per unit of area versus gate voltage overdrive for measured stacked nanowires with channel length of $100 \mathrm{~nm}$ and difference between the fin width masks of $50 \mathrm{~nm}$. Modeled result is represented in line, indicating extracted EOT of $1.15 \mathrm{~nm}$ (solid line) and a dispersion of $\pm 0.1 \mathrm{~nm}$ (dashed lines).

\section{B. Modified Shift and Ratio method}

In this section we present a new approach to implement $S \& R$, taking into account the mobility degradation with $\mathrm{V}_{\mathrm{GS}}$, which may vary significantly among the nanowires. Moreover, the proposed procedure considers all devices as reference, after analyzing two transistors per time, using the difference among the fin width masks to obtain the final mismatch between mask and real fin widths.

Starting from the basic drain current equation at linear regime, if $\mu_{\mathrm{eff}}$ is function of $\mathrm{V}_{\mathrm{GS}}, \mathrm{I}_{\mathrm{DS}}\left(\mathrm{V}_{\mathrm{GS}}\right)$ is given by

$$
\mathrm{I}_{\mathrm{DS}}\left(\mathrm{V}_{\mathrm{GS}}\right)=\frac{\mu_{\mathrm{eff}}\left(\mathrm{V}_{\mathrm{GS}}\right) \times \mathrm{C}_{\mathrm{OX}} \times \mathrm{W}_{\mathrm{eff}}}{\mathrm{L}}\left(\mathrm{V}_{\mathrm{GS}^{-}}-\mathrm{V}_{\mathrm{TH}^{-}} \frac{\mathrm{V}_{\mathrm{DS}}}{2}\right) \times \mathrm{V}_{\mathrm{DS}}
$$

The derivative of the total resistance $(S)$ and the total resistance $\left(\mathrm{R}_{\mathrm{T}}\right)$ are given by (3) and (4), respectively.

$$
\begin{gathered}
\mathrm{S}\left(\mathrm{V}_{\mathrm{GS}}\right)=\frac{\partial \mathrm{R}_{\mathrm{T}}}{\partial \mathrm{V}_{\mathrm{GS}}} \\
\mathrm{R}_{\mathrm{T}}\left(\mathrm{V}_{\mathrm{GS}}\right)=\frac{\mathrm{V}_{\mathrm{DS}}}{\mathrm{I}_{\mathrm{DS}}\left(\mathrm{V}_{\mathrm{GS}}\right)}
\end{gathered}
$$

From (2), (3) and (4), S can be written as

$$
\mathrm{S}\left(\mathrm{V}_{\mathrm{GS}}\right)=\frac{-\mathrm{L}}{\mu_{\mathrm{eff}}\left(\mathrm{V}_{\mathrm{GS}}\right) \times \mathrm{C}_{\mathrm{OX}} \times \mathrm{W}_{\mathrm{eff}} \times\left(\mathrm{V}_{\mathrm{GS}}-\mathrm{V}_{\mathrm{TH}^{-}} \frac{\mathrm{V}_{\mathrm{DS}}}{2}\right)}\left(\frac{\frac{\partial \mu_{\mathrm{eff}}}{\partial \mathrm{V}_{\mathrm{GS}}}}{\mu_{\mathrm{eff}}\left(\mathrm{V}_{\mathrm{GS}}\right)}+\frac{1}{\mathrm{~V}_{\mathrm{GS}}-\mathrm{V}_{\mathrm{TH}^{-}} \frac{\mathrm{V}_{\mathrm{DS}}}{2}}\right)
$$

where $\mathrm{C}_{\mathrm{OX}}$ is the gate oxide capacitance and $\mathrm{V}_{\mathrm{TH}}$ is the threshold voltage. 
The ratio of the derivative of the total resistance between two devices, discerned by indexes " 0 " and " $i$ ", is

$$
\mathrm{r}\left(\delta=\mathrm{V}_{\mathrm{TH}, 0}-\mathrm{V}_{\mathrm{TH}, \mathrm{i}}\right)=\frac{\mathrm{S}_{0}\left(\mathrm{~V}_{\mathrm{GS}}\right)}{\mathrm{S}_{\mathrm{i}}\left(\mathrm{V}_{\mathrm{GS}}\right)}=\frac{\mu_{\mathrm{eff}, \mathrm{i}}{ }^{2}\left(\mathrm{~V}_{\mathrm{GS}}\right) \times \mathrm{W}_{\mathrm{eff}, \mathrm{i}}}{\mu_{\mathrm{eff}, 0}{ }^{2}\left(\mathrm{~V}_{\mathrm{GS}}\right) \times \mathrm{W}_{\mathrm{eff}, 0}}\left(\frac{\frac{\partial \mu_{\mathrm{eff}, 0}}{\partial \mathrm{V}_{\mathrm{GS}}} \times\left(\mathrm{V}_{\mathrm{GS}}-\mathrm{V}_{\mathrm{TH}, 0^{-}}-\frac{\mathrm{V}_{\mathrm{DS}}}{2}\right)+\mu_{\mathrm{eff}, 0}\left(\mathrm{~V}_{\mathrm{GS}}\right)}{\frac{\partial \mu_{\mathrm{eff}, \mathrm{i}}}{\partial \mathrm{V}_{\mathrm{GS}}} \times\left(\mathrm{V}_{\mathrm{GS}}-\mathrm{V}_{\mathrm{TH}, \mathrm{i}^{-}} \frac{\mathrm{V}_{\mathrm{DS}}}{2}\right)+\mu_{\mathrm{eff}, \mathrm{i}}\left(\mathrm{V}_{\mathrm{GS}}\right)}\right)
$$

where $\delta$ indicates that $\mathrm{V}_{\mathrm{GS}}$ of the device with index " $\mathrm{i}$ ” must be shifted in $\mathrm{V}_{\mathrm{TH}, 0}-\mathrm{V}_{\mathrm{TH}, \mathrm{i}}[11]$.

$\mathrm{S}_{0}\left(\mathrm{~V}_{\mathrm{GS}}\right)$ and $\mathrm{S}_{\mathrm{i}}\left(\mathrm{V}_{\mathrm{GS}}-\delta\right)$ are obtained from the experimental $\mathrm{I}_{\mathrm{DS}}\left(\mathrm{V}_{\mathrm{GS}}\right)$ curves, through (3), after series resistance correction, and then compared to (6). The experimental $\mathrm{I}_{\mathrm{DS}}$ can be corrected by the usual expression

$$
\mathrm{I}_{\mathrm{DS}, \mathrm{c}}\left(\mathrm{V}_{\mathrm{GS}}\right)=\frac{\mathrm{I}_{\mathrm{DS}}\left(\mathrm{V}_{\mathrm{GS}}\right)}{1-\mathrm{R}_{\mathrm{S}} \frac{\mathrm{I}_{\mathrm{DS}}\left(\mathrm{V}_{\mathrm{GS}}\right)}{\mathrm{V}_{\mathrm{DS}}}}
$$

where $I_{D S, c}$ indicates $I_{D S}$ after series resistance correction and $R_{S}$ can be extracted through different methods. The series resistance of the studied stacked nanowires and the method used for extraction are shown in section D.

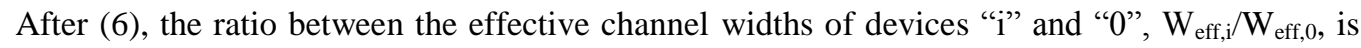
obtained. To improve the accuracy of the extraction, each studied stacked nanowire, indexed by "i", is compared to several others, indexed by " 0 ", i. e. different reference devices are considered. Figure 4 shows the extracted $\mathrm{W}_{\mathrm{eff}, \mathrm{i}} / \mathrm{W}_{\mathrm{eff}, 0}$ as a function of the fin width mask of the studied device $\left(\mathrm{W}_{\mathrm{FIN}, \text { mask, } \mathrm{i}}\right)$, for stacked NWs with $\mathrm{L}=100 \mathrm{~nm}$, taking three different NWs as references, $\mathrm{W}_{\mathrm{FIN}, \text { mask,0 }}=10,40$ and $60 \mathrm{~nm}$. Note that $\mathrm{W}_{\text {eff, },} / \mathrm{W}_{\mathrm{eff}, 0}$ is equal to 1 when $\mathrm{W}_{\mathrm{FIN}, \text { mask, } \mathrm{i}}=\mathrm{W}_{\mathrm{FIN}, \text { mask, } 0 \text {. }}$

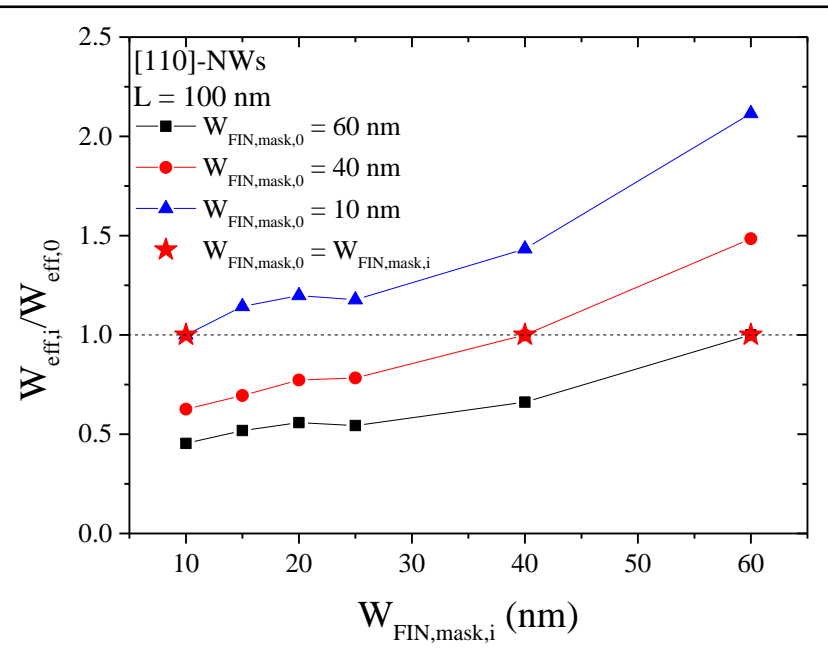

Figure 4. Extracted effective channel width ratio versus the fin width mask of the studied device, considering references stacked nanowires with fin width mask of 10, 40 and $60 \mathrm{~nm}$. A dotted line for y axis equal to 1 indicates when reference and studied devices are the same. Channel length is $100 \mathrm{~nm}$. 
Instead of attributing a given fin width for any of the reference devices, the difference between the fin width masks, $\Delta \mathrm{W}=\mathrm{W}_{\mathrm{FIN}, \text { mask,0 }}-\mathrm{W}_{\mathrm{FIN}, \text { mask,i }}$, will be used to extract the real fin width of each stacked NW, as indicated below:

$$
\begin{gathered}
\frac{\mathrm{W}_{\text {eff,i }}}{\mathrm{W}_{\text {eff }, 0}}=\frac{4 \mathrm{t}_{\mathrm{Si}}+3 \mathrm{~W}_{\mathrm{FIN}}}{4 \mathrm{t}_{\mathrm{Si}}+3 \mathrm{~W}_{\mathrm{FIN}}+3 \Delta \mathrm{W}} \\
\mathrm{W}_{\mathrm{FIN}}=\frac{\frac{\mathrm{W}_{\text {eff }, \mathrm{i}}\left(4 \mathrm{t}_{\mathrm{Si}}+3 \Delta \mathrm{W}\right)-4 \mathrm{t}_{\mathrm{Si}}}{3 \times\left(1-\frac{\mathrm{W}_{\text {eff }, \mathrm{i}}}{\mathrm{W}_{\text {eff }, 0}}\right)}}{3}
\end{gathered}
$$

A systematical procedure to extract $\mathrm{W}_{\mathrm{FIN}}$ through (9) is then applied. Two devices are analyzed per time, until all NWs are compared among them and considered both $\mathrm{W}_{\mathrm{FIN}, \mathrm{mask}, \mathrm{i}}$ and $\mathrm{W}_{\mathrm{FIN}, \text { mask,0} \text {. }}$ Moreover, samples with the same fin width mask are studied in different dies and plotted as a function of the fin width mask, as indicated in Figure 5. A constant mismatch is considered for all $\mathrm{W}_{\mathrm{FIN}}$, as expected after process fabrication, once all the silicon fins are defined after the same etching step. Finally, from the analysis of the obtained results, an average mismatch of $5 \mathrm{~nm}$ is observed in the real physical $\mathrm{W}_{\text {FIN }}$, in respect to the mask values, as highlighted by the dashed line in Figure 5.

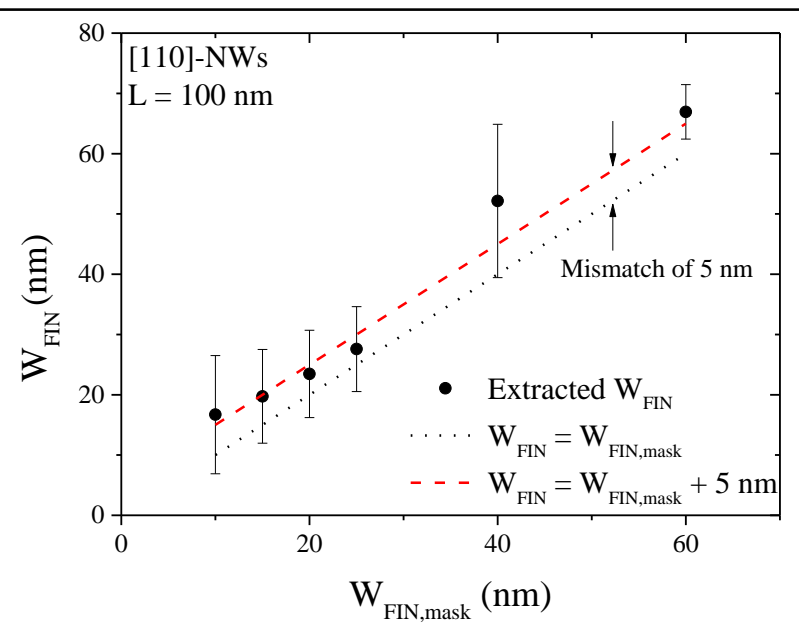

Figure 5. Extracted fin width versus the fin width mask for stacked NWs with channel length of $100 \mathrm{~nm}$ The dotted line indicates the ideal case where no mismatch is observed comparing extracted and mask values of $\mathrm{W}_{\mathrm{FIN}}$. The dashed line indicates a constant mismatch of $5 \mathrm{~nm}$ between extracted and mask values of $\mathrm{W}_{\text {FIN }}$, which fits well the extracted $\mathrm{W}_{\text {FIN }}$ results.

In order to confirm the extracted results of EOT and fin width mismatch, tridimensional numerical simulations were performed using Sentaurus Device Simulator, from Synopsys [15]. Simulations were carried out with quantum effects and the structures were generated through Sentaurus Process, from Synopsys [16]. 
Figure 6 presents $\mathrm{C}_{\mathrm{GC}}$ as a function of $\mathrm{V}_{\mathrm{GT}}$ for simulated stacked NWs with $\mathrm{W}_{\mathrm{FIN}}=15 \mathrm{~nm}$ and EOT of $1.15 \pm 0.1 \mathrm{~nm}$ (a) and EOT $=1.15 \mathrm{~nm}$ and $\mathrm{W}_{\mathrm{FIN}}=15 \pm 3 \mathrm{~nm}$ (b). Symbols indicate measurements for devices with $\mathrm{W}_{\mathrm{FIN} \text {,mask }}=10 \mathrm{~nm}$. All simulated and measured devices present $\mathrm{L}=100 \mathrm{~nm}$. The dashed lines in Figure 6.a represent numerical simulations considering the dispersion of $\pm 0.1 \mathrm{~nm}$ on EOT found with the method applied in Section A. The dashed lines in Figure 6.b indicate numerical simulations resulted from the dispersion of $\pm 3 \mathrm{~nm}$ on $\mathrm{W}_{\mathrm{FIN}}$, which was necessary to describe all the $\mathrm{C}_{\mathrm{GC}}\left(\mathrm{V}_{\mathrm{GS}}\right)$ curves keeping EOT constant at $1.15 \mathrm{~nm}$. As good description of the measured results were obtained with the tridimensional numerical simulations and small dispersion has been obtained, it is possible to conclude that EOT equal to $1.15 \mathrm{~nm}$ and fin width mismatch of $5 \mathrm{~nm}$ can be adopted to express the real physical characteristics of the measured stacked NWs. Although EOT extraction and modified Shift and Ratio methodologies are presented for [110]-oriented NWs, the same results are observed for [100]-NWs because all nanowires in both orientations present similar $\mathrm{C}-\mathrm{V}$ curves, which is expected since they were fabricated together in the same wafer.
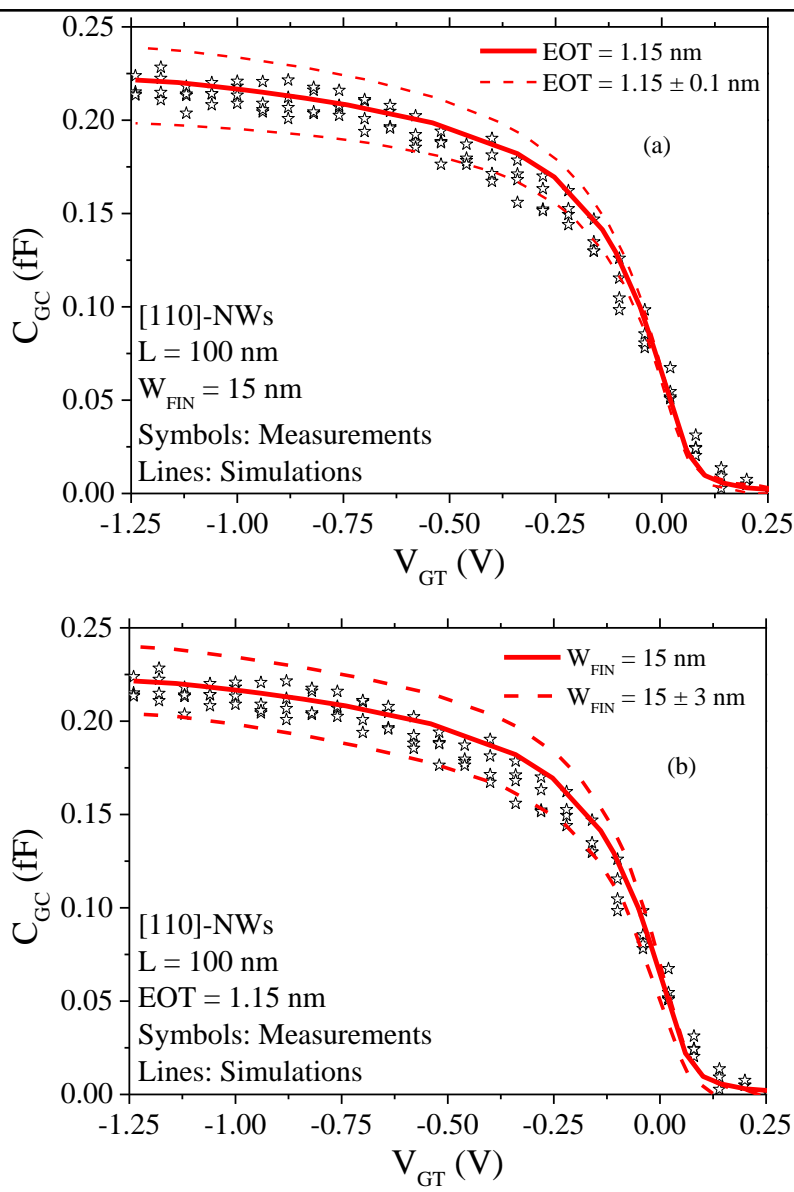

Figure 6. Total gate to channel capacitance versus gate voltage overdrive for measured stacked NWs and simulation. Devices have been simulated with fin width of $15 \mathrm{~nm}$ and EOT of $1.15 \pm 0.1 \mathrm{~nm}$ (a) and EOT $=1.15 \mathrm{~nm}$ and $\mathrm{W}_{\mathrm{FIN}}=15 \pm 3 \mathrm{~nm}$ (b). Channel length is $100 \mathrm{~nm}$. 


\section{Basic parameters extraction}

Figure 7 shows schematics of triple gate nanowires oriented in both [110] and [100] directions. Since the conventional channel orientation for MOSFETs is [110], transistors oriented in [100] direction are rotated in $45^{\circ}$ with respect to [110]-MOSFETs $\left(0^{\circ}\right)$. It is observed that [110]-oriented NWs present top and lateral surfaces at (100) and (110) plans, respectively, while [100]-oriented NWs present both top and lateral surfaces at (100) plan. The holes mobility is higher in the (110)-oriented sidewalls in comparison to (100) plan, so [110] is the preferred orientation for p-type NWs [17].

The vertically stacked nanowires analyzed in this work have 4 lateral channels and 3 channels parallel to the top surface. By increasing $\mathrm{W}_{\mathrm{FIN}}$, the top surface contribution increases as well, which means that as [110]-NWs become narrower, the overall holes mobility is expected to improve due to increase of (110) plan contribution. On the other hand, as [100]-NWs present all 7 channels at (100) plan, $\mu_{\text {eff }}$ is expected to be constant with $\mathrm{W}_{\text {FIN }}$ variation.

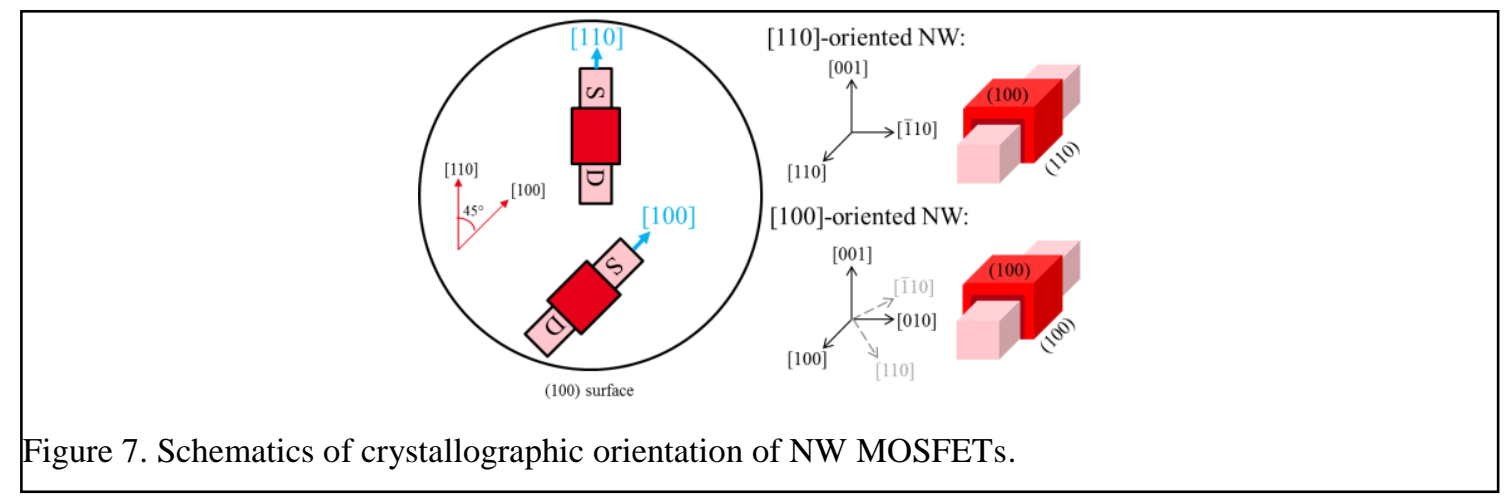

The drain current as a function of $\mathrm{V}_{\mathrm{GS}}$ for stacked NWs with $\mathrm{L}=100$ and $30 \mathrm{~nm}$ are presented in

Figure 8. Both channel orientations are compared at small (a) and strong (b) horizontal electric field, $\mathrm{V}_{\mathrm{DS}}$ of $-40 \mathrm{mV}$ and $-0.9 \mathrm{~V}$, respectively. As all devices present the same $\mathrm{W}_{\mathrm{FIN}}$ but different $\mathrm{L}$, IDS was multiplied by the channel length to emphasize that shorter NWs present lower $\left|I_{D S}\right| . L$ due to mobility degradation and increase of series resistance effect. As discussed in Figure 7, higher drain current is observed for stacked [110]-NWs due to higher holes mobility in (110) plan in comparison to (100) plan. Additionally, [18] reported that uniaxial compressive stress, induced in the channel by SiGe source and drain, degrades holes mobility in [100]-oriented NWs. It has been verified that the longitudinal piezoresistive coefficients of [100]-oriented NWs $\left(\pi_{\mathrm{L}, \mathrm{NW}}{ }^{[100]}\right)$ decrease with $\mathrm{W}_{\mathrm{FIN}}$ reduction, reaching high negative values, which characterizes tensile stress. Figure 5 in [18] shows $\pi_{\mathrm{L}, \mathrm{Nw}}{ }^{[100]}<0$ and clearly indicates detrimental contribution of the applied stress, corroborating with the measured results. 

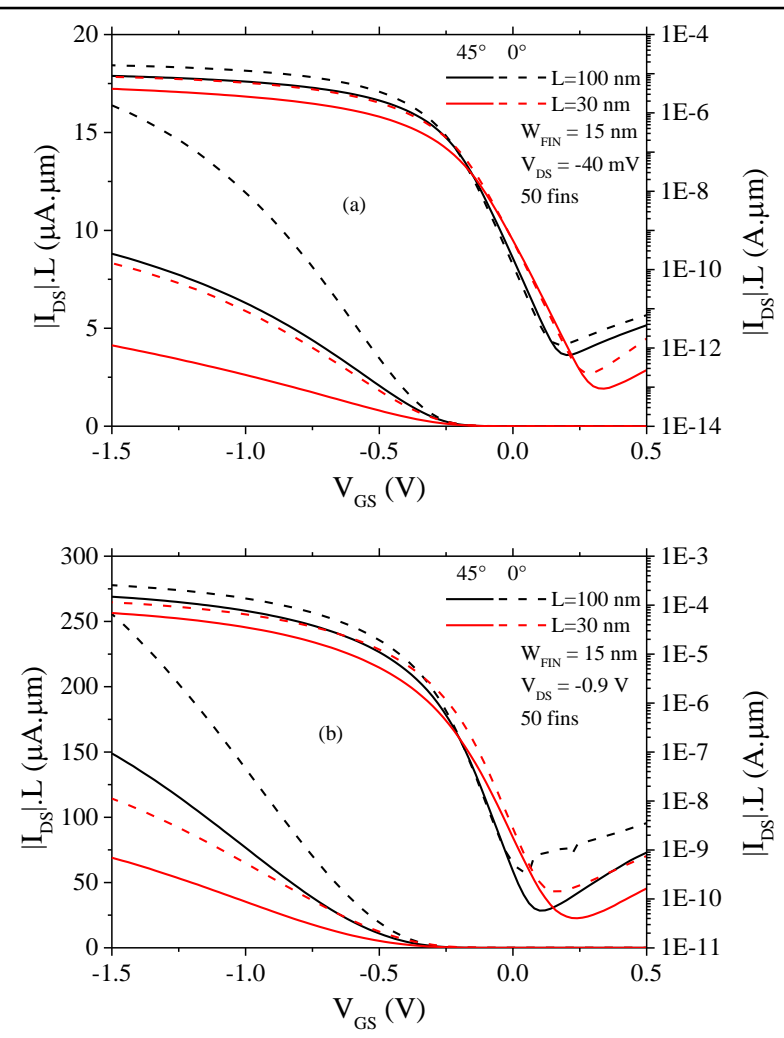

Figure 8. Drain current normalized by the channel length versus the gate voltage at low (a) and high (b) drain voltage. Stacked NWs oriented in both [110] and [100] directions. Channel lengths of 100 and 30 $\mathrm{nm}$ and fin width of $15 \mathrm{~nm}$.

Figure 9 presents $\mathrm{I}_{\mathrm{OFF}} / \mathrm{W}_{\text {eff }}$ as a function of $\mathrm{I}_{\mathrm{ON}} / \mathrm{W}_{\text {eff }}$ (a) and $\mathrm{I}_{\mathrm{ON}} / \mathrm{I}_{\mathrm{OFF}}$ as a function of $\mathrm{W}_{\mathrm{FIN}}$ (b) for $\mathrm{L}=30 \mathrm{~nm}$, at $\mathrm{V}_{\mathrm{DS}}=-0.9 \mathrm{~V}$. The off-state and on-state currents were extracted at $\mathrm{V}_{\mathrm{GS}}=0$ and $-0.9 \mathrm{~V}$, respectively. Figure 9.a presents not only the results normalized by $\mathrm{W}_{\text {eff, }}$ but also by $\mathrm{W}_{\mathrm{FIN}}$ for transistors with $\mathrm{W}_{\mathrm{FIN}}=15 \mathrm{~nm}$. The normalization of $\mathrm{I}_{\mathrm{ON}}$ by $\mathrm{W}_{\text {eff }}$ has an important physical meaning, once it calculates the amount of current per micrometer that flows considering all the seven conduction channels formed in both bottom and top levels. On the other hand, stacking two or more levels aims to increase the current by top view area, which can be evaluated only by normalizing Ion by $\mathrm{W}_{\mathrm{FIN}}$. $\mathrm{IoN}_{\mathrm{N}} / \mathrm{W}_{\text {eff }}$ of [110]oriented NWs reaches up to $450 \mu \mathrm{A} / \mu \mathrm{m}$, while $\mathrm{I}_{\mathrm{ON}} / \mathrm{W}_{\mathrm{FIN}}$ can reach up to $2500 \mu \mathrm{A} / \mu \mathrm{m}$, in comparison to

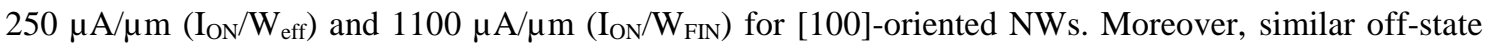
current for both channel orientations is observed in Figure 9.a and Figure 9.b shows IoN/IOFF ratio in the order of $\sim 10^{4}$, higher for [110]-oriented NWs and increasing with $\mathrm{W}_{\text {FIN }}$ reduction. By scaling $\mathrm{W}_{\mathrm{FIN}}$ from $65 \mathrm{~nm}$ down to $15 \mathrm{~nm}$, improvements of 6.3 and 14.1 times are obtained for [110]- and [100]-oriented NWs. $\mathrm{I}_{\mathrm{ON}} / \mathrm{I}_{\mathrm{OFF}}$ improvements with $\mathrm{W}_{\mathrm{FIN}}$ reduction are related to the subthreshold slope decrease, which reduces $\mathrm{I}_{\mathrm{OFF}}$, and holes mobility increase, which increases $\mathrm{I}_{\mathrm{ON}}$. 

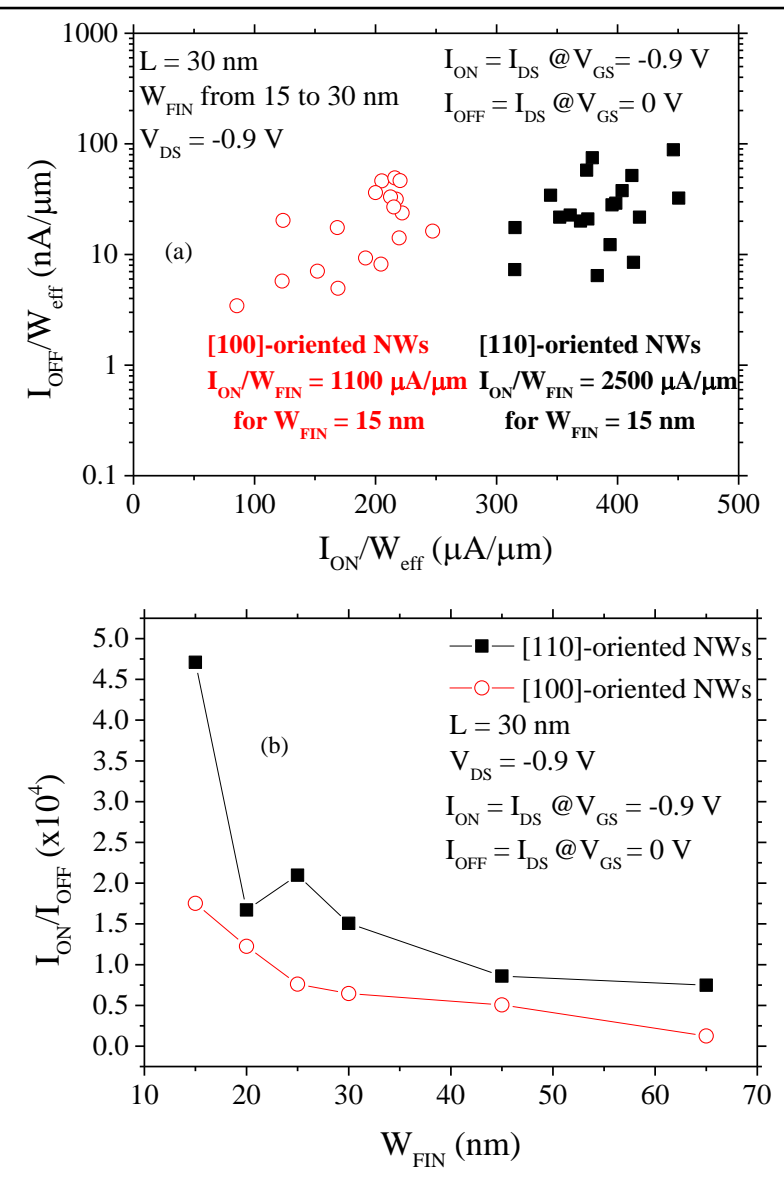

Figure 9. Off-state current versus on-state current (a) and current ratio versus fin width (b) for [110]- and [100]-oriented stacked NWs with channel length of $30 \mathrm{~nm}$. The on-state current normalized by the fin width for NWs with fin width of $15 \mathrm{~nm}$ is indicated in (a).

In order to evaluate the short channel effects the stacked NWs may suffer varying L, Figure 10 shows $\mathrm{V}_{\mathrm{TH}}(\mathrm{a})$, SS (b) and $|\mathrm{DIBL}|$ (c) as a function of L, for [110]- and [100]-oriented NWs with $\mathrm{W}_{\mathrm{FIN}}=$ 15, 25 and $65 \mathrm{~nm}$. Threshold voltage was extracted by the second derivative method [19]. It is observed that very small $\mathrm{V}_{\mathrm{TH}}$ roll-off (lower than $60 \mathrm{mV}$ or $24 \%$ with respect to the longest device) and subthreshold slope degradation (lower than $18 \mathrm{mV} / \mathrm{dec}$ or $26 \%$ with respect to the longest device) are observed while reducing $\mathrm{L}$ down to $15 \mathrm{~nm}$ for [110]-oriented NWs with $\mathrm{W}_{\mathrm{FIN}}$ of $25 \mathrm{~nm}$, whose $\mathrm{SS}$ is lower than $88 \mathrm{mV} / \mathrm{dec}$ and $|\mathrm{DIBL}|$ is lower than $100 \mathrm{mV} / \mathrm{V}$. Besides both [110] and [100] channel orientations exhibit similar results, as predicted by the logarithmic scaled curves in Figure 8, SS and DIBL results for [100]-oriented NWs with $\mathrm{W}_{\mathrm{FIN}}$ of $65 \mathrm{~nm}$ present higher degradation as $\mathrm{L}$ reduces in comparison to [110]-NWs. 


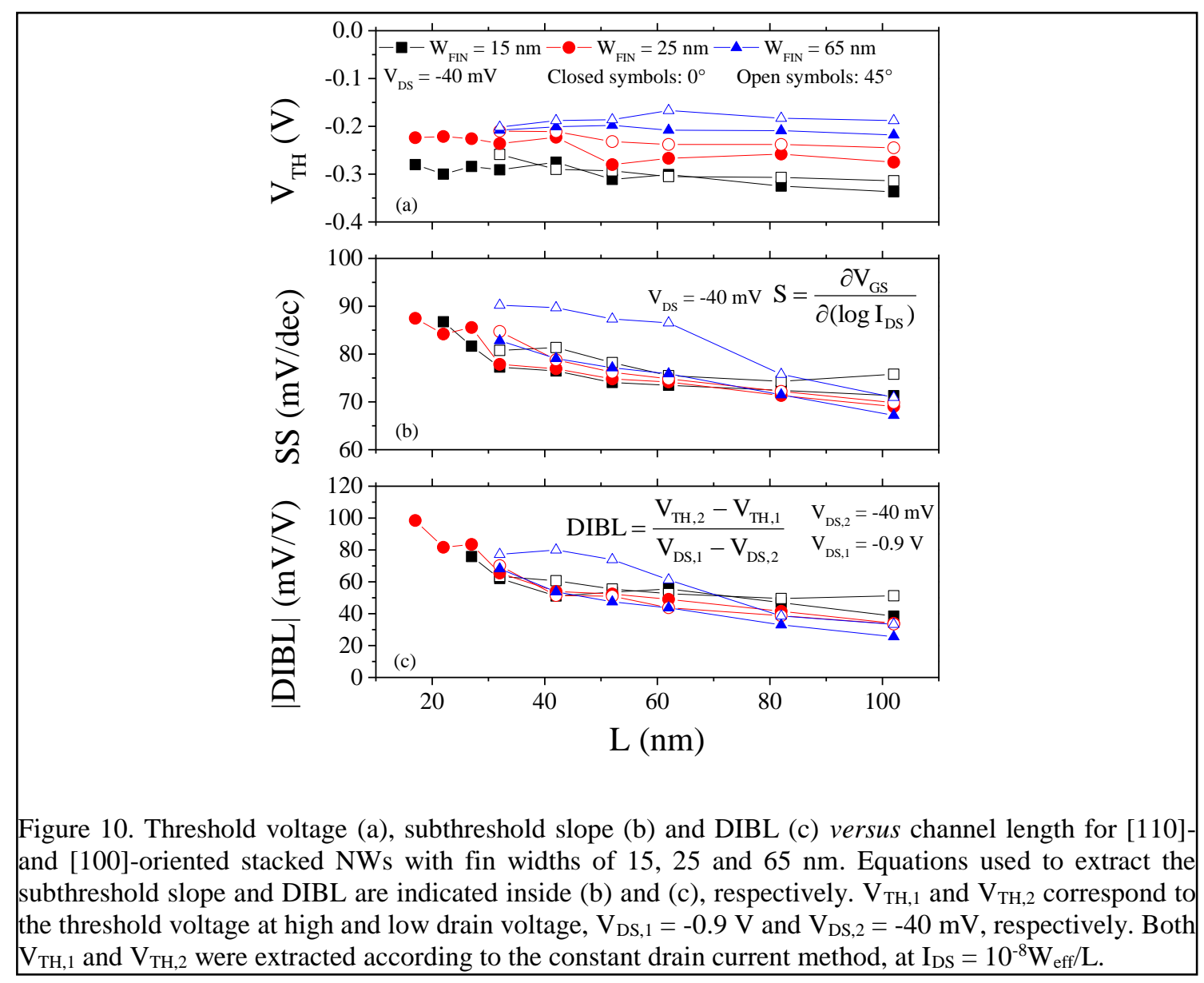

To evaluate the fin width influence on the SCEs, Figure 11 shows $\mathrm{V}_{\mathrm{TH}}$ (a), SS (b) and |DIBL| (c) as a function of $\mathrm{W}_{\mathrm{FIN}}$, for [110]- and [100]-oriented NWs with $\mathrm{L}=30,60$ and $100 \mathrm{~nm}$. One can note that $\mathrm{V}_{\mathrm{TH}}$ varies around $150 \mathrm{mV}$, comparing $\mathrm{W}_{\mathrm{FIN}}=65$ and $15 \mathrm{~nm}$. Through both $\mathrm{SS}$ and |DIBL|, it is observed approximately constant dependence with $\mathrm{W}_{\text {FIN }}$ for $\mathrm{L}=100 \mathrm{~nm}$ and $60 \mathrm{~nm}$. For $\mathrm{L}=30 \mathrm{~nm}, 5$ and 10 $\mathrm{mV} / \mathrm{dec}$ of improvement are obtained for SS scaling $\mathrm{W}_{\mathrm{FIN}}$ down to $15 \mathrm{~nm}$, for [110]- and [100]-oriented NWs, respectively. Stronger short channel effects immunity with $\mathrm{W}_{\mathrm{FIN}}$ reduction is due to improved electrostatic integrity provided by the better gate control over the charges in the channel region [20]. The subthreshold slope reduction strongly improves the off-state current and the higher SS decrease of [100]oriented NWs corroborates with their $\mathrm{I}_{\mathrm{ON}} / \mathrm{I}_{\mathrm{OFF}}$ increase (14.1 times in comparison to 6.3 times for [110]oriented NWs, from $\mathrm{W}_{\mathrm{FIN}}=65$ down to $15 \mathrm{~nm}$ as discussed in Figure 9). 


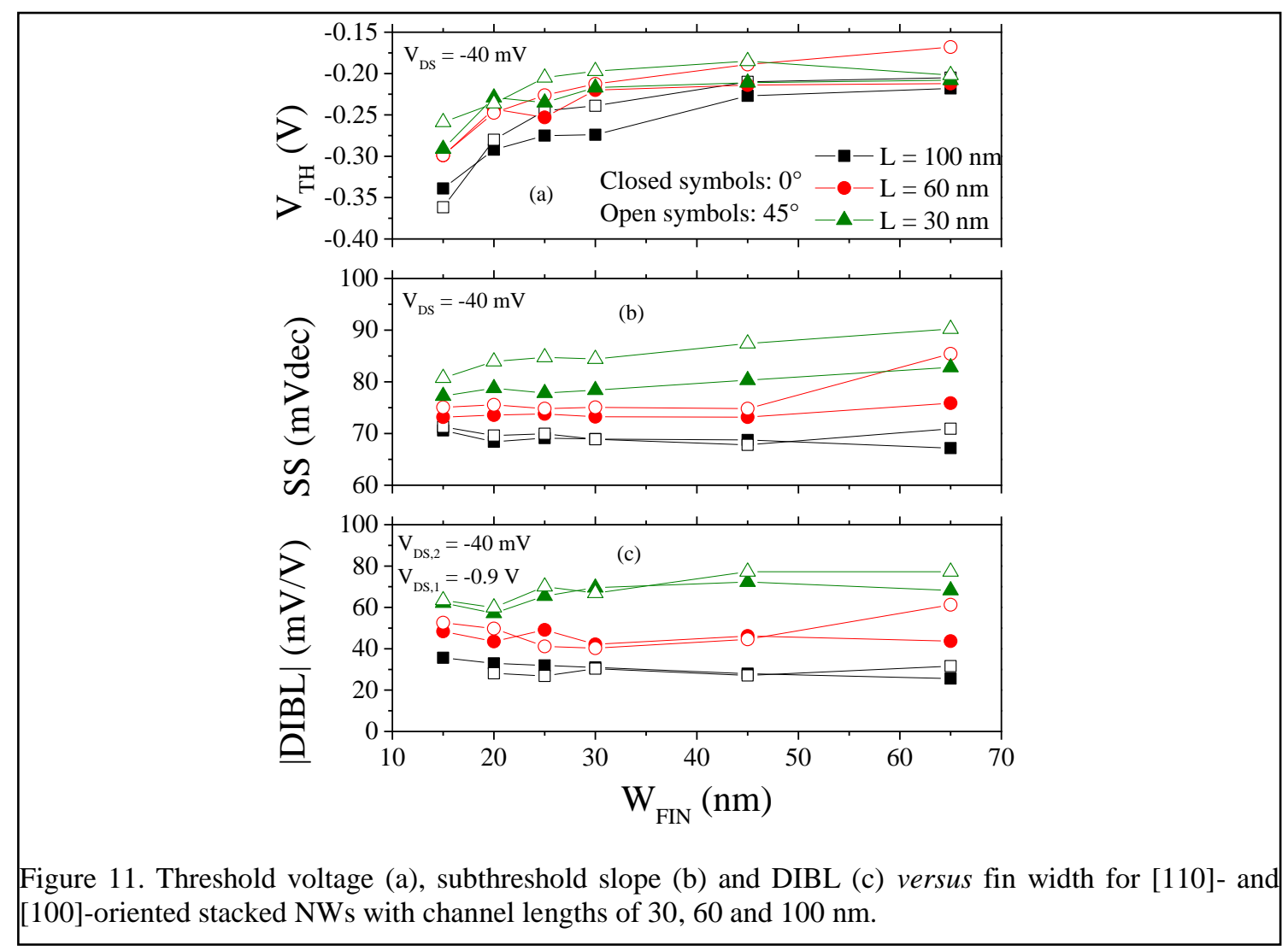

The overall behavior of all parameters $\left(\mathrm{V}_{\mathrm{TH}}, \mathrm{SS}\right.$ and DIBL) varying both $\mathrm{W}_{\text {FIN }}$ and $\mathrm{L}$ should be similar between vertically stacked nanowires and GAA devices, since the studied NWs are narrow, the $\Omega$ shaped level may induce significant gate control in the bottom surface channel, presenting similar behavior to GAA MOSFETs. Optimized vertically stacked structures would be able to deliver not only high drain current levels due to wide $\mathrm{W}_{\text {eff }}$, but also better results for SCE than FinFET-like devices with similar dimensions for $\mathrm{W}_{\mathrm{FIN}}$ and thicker silicon thickness, once the sum of $\Omega$-shaped bottom level and GAA top level provide better electrostatic coupling improvements for short channel transistors.

\section{Transport parameters extraction}

Figure 12 shows the results for the total resistance, calculated by (4) and normalized by $\mathrm{W}_{\text {eff, }}$ as a function of the inverse of the NW gain $\left(\beta=\mu_{\text {eff }} \mathrm{C}_{\mathrm{ox}} \mathrm{W}_{\mathrm{eff}} / \mathrm{L}\right)$, for [110]- (a) and [100]-oriented (b) NWs, $\mathrm{V}_{\mathrm{DS}}=-40 \mathrm{mV}$ and $\mathrm{V}_{\mathrm{GT}}=-1 \mathrm{~V}$. In these figures the solid straight lines were plotted through the linear regression of all measured data points for each $\mathrm{W}_{\mathrm{FIN}}$. The gain of the transistors was extracted following the Y-function method [10] and the crossing points of the straight lines with the y-axis indicate the series resistance. Although some dispersion of the data is observed mainly for narrower transistors, good linearity allowed the extraction of $\mathrm{R}_{\mathrm{S}}$ values around 140 and $360 \Omega \mu \mathrm{m}$, for [110]- and [100]-oriented 
NWs, respectively. Approximately the same $\mathrm{R}_{\mathrm{T}} \cdot \mathrm{W}_{\text {eff }}$ values at $1 / \beta=0$ are obtained for all $\mathrm{W}_{\mathrm{FIN}}$ studied, from 15 to $65 \mathrm{~nm}$, indicating that $\mathrm{R}_{\mathrm{S}}$ scales with $\mathrm{W}_{\mathrm{FIN}}$ for the entire range of $\mathrm{L}$, from 100 down to $15 \mathrm{~nm}$.

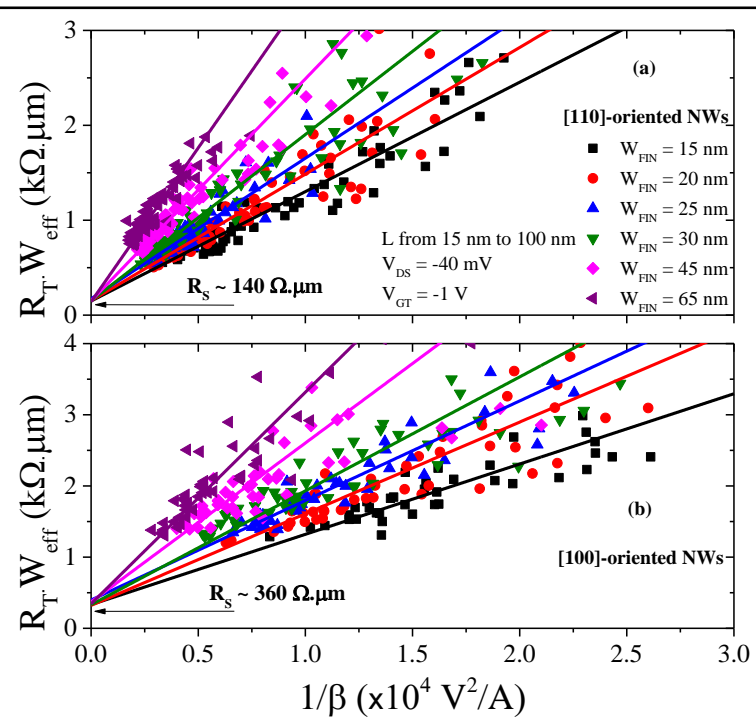

Figure 12. Normalized total resistance versus the inverse of gain for [110]- (a) and [100]-oriented (b) NWs. Channel length varies from 15 to $100 \mathrm{~nm}$. Fin width equals to 15, 20, 25, 30, 45 and $65 \mathrm{~nm}$. Extracted series resistance of 140 and $360 \Omega \mu \mathrm{m}$ for [110]- and [100]-oriented NWs, respectively.

After correcting the series resistance effect in the I-V characteristics using (7), a study of the effective holes mobility was performed. Figure 13 shows $\mu_{\mathrm{eff}}$ as a function of the inversion carrier density ( $\mathrm{N}_{\text {inv }}$ ) extracted by split-CV technique [21] for [110]- and [100]-oriented NWs, with L = $100 \mathrm{~nm}$ and $\mathrm{W}_{\text {FIN }}$ $=15 \mathrm{~nm}$. It is indicated that a factor close to 2 separates the maximum mobility for devices in [110] and [100] direction, which agrees with the results obtained for the drain current in Figure 8. The stacked nanowires with channel orientation in [110] direction present higher mobility, lower series resistance and slightly lower subthreshold slope (Figure 11.b), which explains $\mathrm{I}_{\mathrm{ON}} / \mathrm{W}_{\text {eff }}$ results obtained in Figure 9.

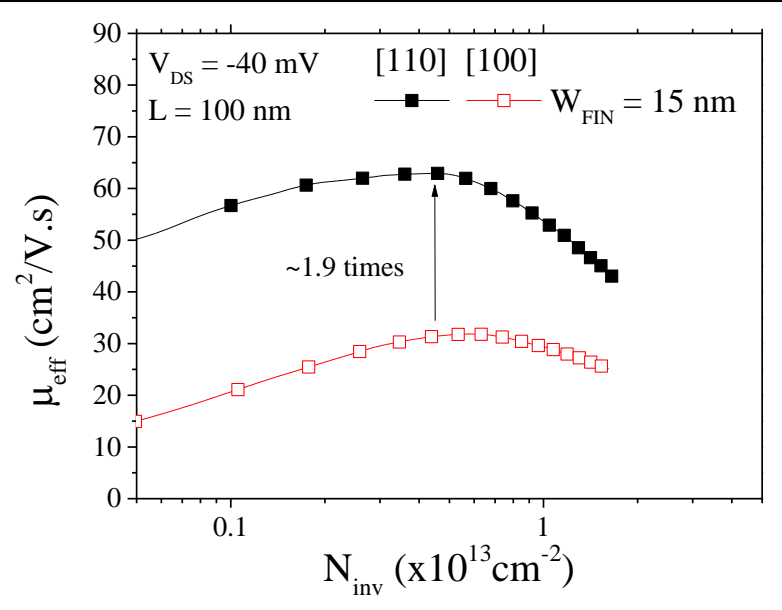

Figure 13. Effective holes mobility versus inversion carrier density for [110]- and [100]-oriented stacked $\mathrm{NWs}$ with channel length of $100 \mathrm{~nm}$ and fin width of $15 \mathrm{~nm}$. Drain voltage is $-40 \mathrm{mV}$. 
Figure 14 presents $\mu_{\text {eff }}$ as a function of L (a), extracted by Y-function method, and as a function of $\mathrm{W}_{\mathrm{FIN}}(\mathrm{b})$, extracted by split-CV technique. From Figure 14.a, it is observed that mobility is higher for [110]-oriented NWs although they present significant degradation for L $<60 \mathrm{~nm}$. For [100]-oriented NWs, mobility is almost constant down to $\mathrm{L}=30 \mathrm{~nm}$, and similar values are obtained varying $\mathrm{N}_{\text {inv }}$, as expected from Figure 13, where one can note small degradations of $\mu_{\text {eff }}$ varying $\mathrm{N}_{\text {inv. }}$. Figure 14 .b shows improvements of up to $17 \%$ with $\mathrm{W}_{\text {FIN }}$ reduction for [110]-NWs, while [100]-NWs show approximately constant behavior, which is agreement with triple gate MOSFETs results [22]. These results indicate that benefits of scaling $\mathrm{W}_{\mathrm{FIN}}$ down to $15 \mathrm{~nm}$ observed in $\mathrm{I}_{\mathrm{ON}} / \mathrm{I}_{\mathrm{OFF}}$ (Figure 9.b) are more related to subthreshold slope improvements (decrease of $\mathrm{I}_{\mathrm{OFF}}$ ) than mobility increase (increase of $\mathrm{I}_{\mathrm{ON}}$ ), especially for [100] channel orientation.
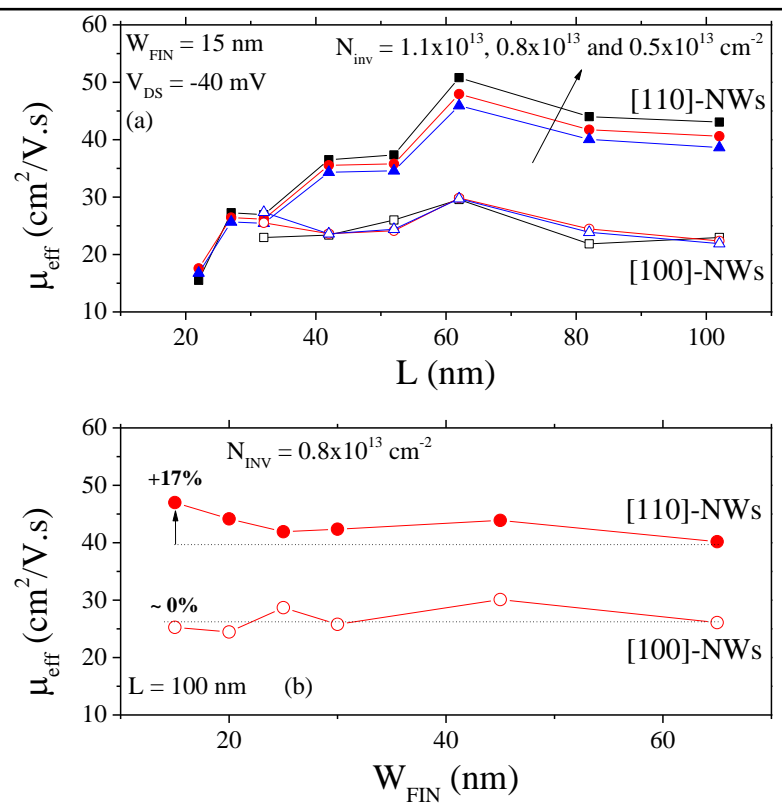

Figure 14. Effective holes mobility versus channel length (a) and fin width (b) for [110]- and [100] oriented stacked NWs, at drain voltage of $-40 \mathrm{mV}$.

\section{CONCLUSIONS}

This paper depicted the electrical characteristics of vertically stacked p-type nanowires fabricated with inner spacers and $\mathrm{SiGe}$ source/drain, as a function of channel length and fin width. To allow for accurate data interpretation, EOT extraction and Shift and Ratio method have been successfully adapted and validated.

High $\mathrm{I}_{\mathrm{ON}} / \mathrm{W}_{\mathrm{FIN}}$ has been obtained in two levels stacked NWs (up to $2500 \mu \mathrm{A} / \mu \mathrm{m}$ for [110]-NWs with $\mathrm{L}=30 \mathrm{~nm}$ and $\mathrm{W}_{\mathrm{FIN}}=15 \mathrm{~nm}$ ), although slightly smaller $\mu_{\mathrm{eff}}$ is expected in comparison to $3 \mathrm{G}$ 
MOSFETs due to stronger top surface (100) contribution. While [110]-oriented 3G MOSFETs have 1 interface (over 3) at the (100) plan, [110]-oriented stacked NWs have 3 interfaces (over 7) at the (100) plan.

Excellent SCE control has been obtained for both [110]- and [100]-oriented NWs due to good electrostatic coupling and channel control provided by the sum of $\Omega$-Gate and GAA wires. This conclusion comes after the evaluation of $\mathrm{V}_{\mathrm{TH}}$, SS and DIBL degradations down to $15 \mathrm{~nm}$ gate length.

Despite complex source and drain engineering, the extracted value of series resistance for [110]stacked NWs $(140 \Omega \mu \mathrm{m})$ are comparable to those obtained for advanced planar MOSFETs. Transport analysis performed through both split-CV and Y-function method allowed to conclude that, on the same way as for 3G NWs, [110] orientation is better for p-type stacked NWs due to holes mobility improvement in (110)-oriented sidewalls.

\section{ACKNOWLEDGEMENTS}

The authors would like to acknowledge the French Public Authorities from NANO 2017 program, CNPq and São Paulo Research Foundation (FAPESP) grants 2015/10491-7 and 2016/06301-0.

This work is also partially funded by the SUPERAID7 (grant $\mathrm{N}^{\circ} 688101$ ) project.

\section{REFERENCES}

[1] J. P. Colinge, M. H. Gao, A. Romano-Rodriguez, H. Maes, and C. Claeys, "Silicon-on-insulator 'gate-all-around device," in Electron Devices Meeting, 1990. IEDM '90. Technical Digest., International, 1990, pp. 595-598.

[2] R. Coquand et al., "Scaling of high-k/metal-gate Trigate SOI nanowire transistors down to 10nm width," in 2012 13th International Conference on Ultimate Integration on Silicon (ULIS), 2012, pp. 37-40.

[3] K. J. Kuhn, “Considerations for Ultimate CMOS Scaling," IEEE Trans. Electron Devices, vol. 59, no. 7, pp. 1813-1828, Jul. 2012.

[4] R. Coquand et al., "Strain-induced performance enhancement of tri-gate and omega-gate nanowire FETs scaled down to 10nm Width," in 2012 Symposium on VLSI Technology (VLSIT), 2012, pp. 1314. 
[5] S. Barraud et al., "Strained Silicon Directly on Insulator N- and P-FET nanowire transistors," in 2014 15th International Conference on Ultimate Integration on Silicon (ULIS), 2014, pp. 65-68.

[6] M. Saitoh et al., "Short-channel performance and mobility analysis of $\langle 110\rangle$ - and $\langle 100\rangle$-oriented tri-gate nanowire MOSFETs with raised source/drain extensions," in 2010 Symposium on VLSI Technology, 2010, pp. 169-170.

[7] H. Mertens et al., "Gate-all-around MOSFETs based on vertically stacked horizontal Si nanowires in a replacement metal gate process on bulk Si substrates," in 2016 IEEE Symposium on VLSI Technology, 2016, pp. 1-2.

[8] C. Dupre et al., "15nm-diameter 3D stacked nanowires with independent gates operation: $\Phi$ FET," in 2008 IEEE International Electron Devices Meeting, 2008, pp. 1-4.

[9] S. Barraud et al., "Vertically stacked-NanoWires MOSFETs in a replacement metal gate process with inner spacer and SiGe source/drain,” in 2016 IEEE International Electron Devices Meeting (IEDM), 2016, p. 17.6.1-17.6.4.

[10] G. Ghibaudo, "New method for the extraction of MOSFET parameters," Electron. Lett., vol. 24, no. 9, pp. 543-545, Apr. 1988.

[11] Y. Taur et al., "A new 'shift and ratio' method for MOSFET channel-length extraction," IEEE Electron Device Lett., vol. 13, no. 5, pp. 267-269, May 1992.

[12] N. Collaert, A. Dixit, K. G. Anil, R. Rooyackers, A. Veloso, and K. De Meyer, "Shift and ratio method revisited: extraction of the fin width in multi-gate devices," Solid-State Electron., vol. 49, no. 5, pp. 763-768, May 2005.

[13] C. Leroux et al., "Characterization and modeling of nanometric SiO2 dielectrics," Microelectron. Eng., vol. 72, no. 1, pp. 121-124, Apr. 2004.

[14] C. Leroux, G. Ghibaudo, G. Reimbold, R. Clerc, and S. Mathieu, "Oxide thickness extraction methods in the nanometer range for statistical measurements," Solid-State Electron., vol. 46, no. 11, pp. 1849-1854, Nov. 2002.

[15] “Sentaurus Device User Guide, Version C-2009.06.” Synopsys, 2009.

[16] “Sentaurus Process User Guide, Version A-2007.12.” Synopsys, 2007.

[17] S. Takagi, A. Toriumi, M. Iwase, and H. Tango, “On the universality of inversion layer mobility in Si MOSFET's: Part II-effects of surface orientation,” IEEE Trans. Electron Devices, vol. 41, no. 12, pp. 2363-2368, Dec. 1994. 
[18] J. Pelloux-Prayer et al., "Study of the piezoresistive properties of NMOS and PMOS $\Omega$-gate SOI nanowire transistors: Scalability effects and high stress level," in Electron Devices Meeting (IEDM), 2014 IEEE International, 2014, p. 20.5.1-20.5.4.

[19] A. Ortiz-Conde, F. J. García Sánchez, J. J. Liou, A. Cerdeira, M. Estrada, and Y. Yue, “A review of recent MOSFET threshold voltage extraction methods," Microelectron. Reliab., vol. 42, no. 4-5, pp. 583-596, Apr. 2002.

[20] J. P. Colinge, FinFETs and Other Multi-Gate Transistors. Springer, 2008.

[21] A. Ohata, M. Cassé, and S. Cristoloveanu, "Front- and back-channel mobility in ultrathin SOIMOSFETs by front-gate split CV method," Solid-State Electron., vol. 51, no. 2, pp. 245-251, Feb. 2007.

[22] J. Pelloux-Prayer et al., "Transport in TriGate nanowire FET: Cross-section effect at the nanometer scale," in 2016 IEEE SOI-3D-Subthreshold Microelectronics Technology Unified Conference (S3S), 2016, pp. 1-2. 